\title{
Epidemiological Study of Bancroftian Filariasis in Recife, Northeastern Brazil
}

\author{
Amélia Maciel, Abraham Rocha, Keyla Belizia F Marzochi*, Zulma Medeiros, \\ Alexandre B Carvalho, Leda Regis, Wayner Souza, Tiago Lapa, \\ André Furtado/ ${ }^{+}$
}

\author{
Centro de Pesquisas Aggeu Magalhães-FIOCRUZ, Caixa Postal 7472, Campus UFPE, 50670-420 Recife, PE, \\ Brasil *Escola Nacional de Saúde Pública, Fundação Oswaldo Cruz, R. Leopoldo Bulhões 1480, 21041-210 \\ Rio de Janeiro, RJ, Brasil
}

Wuchereria bancrofti in Pernambuco was first documented in 1952 (Azevedo \& Dobbin 1952), and since then it has been reported in surveys carried out in selected areas of Recife. Several surveys were carried out from 1981 to 1991 by SUCAM. In the 1985 SUCAM's report the disease is considered under control. The CPqAM Filariasis Research Program was established in 1985 and a filarial survey was carried out in the town of Olinda, Greater Recife. In order to verify the real epidemiological situation, a study was conducted in the city of Recife.

21/36 of the Special Zones of Social Interest (ZEIS), were randomly selected for the present study. From 10,664 persons screened, 683 were positive and the prevalence rate for microfilaraemia (mf) varied from $0.6 \%$ to $14.9 \%$. A mean mf prevalence of $6.5 \%$, showed that the infection occurs in a wide geographic distribution in Greater Recife and that the intensity of transmission is a real and potential threat to public health in affected communities. Mf rate among males and females differed significantly. Due to the rapid increase in population, unplanned urban settlements, poor sanitary facilities and the favorable geographical conditions to the development of the vector, filariasis may actually be increasing in Recife.

Key words: filariasis - Wuchereria bancrofti - Culex quinquefasciatus - epidemiology - sex distribution age distribution

Lymphatic filariasis is an endemic infection associated with three parasites - Wuchereria bancrofti, Brugia malayi and Brugia timori.

The World Health Organization (WHO) estimated 72.8 million persons infected with $W$. bancrofti, and 5.8 millions with $B$. malayi and $B$. timori, among a total of 751 millions exposed (WHO 1992).

The presence of $W$. bancrofti in Brazil was first reported in 1877 (Pessoa 1978) and there is a presupposition that the disease was brought by the African slaves. The city of Salvador, State of Bahia, was the first historic focus of this infection (Parahym 1961).

\footnotetext{
This work was supported by UNPD/World Bank/WHO/ Special Program for Research and Training in Tropical Diseases (TDR), Conselho Nacional de Desenvolvimento Científico e Tecnológico $(\mathrm{CNPq})$ and Fundação de Amparo à Ciência e Tecnologia do Estado de Pernambuco FACEPE.

${ }^{+}$Corresponding author. Fax:

Received 11 October 1995

Accepted 12 February 1996
}

In Recife, northeast of Brazil, the disease was first documented in 1952, when the prevalence rate recorded was 9.7\% (Azevedo \& Dobbin 1952).

In 1954, a large country-wide filarial survey was carried out. High levels of endemicity were found only in the cities of Recife and Belém (north of Brazil), with an estimate that a total of 50,000 to 80,000 persons were infected in both areas (Rachou \& Deane 1954).

A National Program for the Control of Lymphatic Filariasis was created by the National Department of Rural Endemics (DNERu). In 1970 this Department took the name of SUCAM (Health Campaigns Superintendency), at present FNS (National Health Foundation). From 1954 to 1981, there have been eleven filarial surveys in Recife. The crude microfilaraemia rate found during this period ranged between $6.9 \%$ and $2.3 \%$. Finally, in a survey completed in 1983, including active and passive search, 246,818 persons were examined from which 2,477 (1\%) were found positive, indicating that the disease had reached a very low level of endemicity. A detailed epidemiological report, based on data from SUCAM, concluded that the endemy was under control (Ministério da Saúde 1985). 
In May 1986, the CPqAM Filariasis Research Program was established. A filarial survey in Sapucaia, district of Olinda, Greater Recife, utilizing a different method of blood collection and the technique of nuclepore filtration, instead of blood smears, showed values of microfilarial prevalence up to $40 \%$ (Dreyer \& Medeiros 1990).

With the aim of providing both more precise estimates of prevalence in the communities surveyed and its distribution by gender and major agegroup categories overall, in order to offer alternatives for future control programs, a filarial survey covering Recife and Greater Recife was carried out during 1991-1992.

\section{MATERIAL AND METHODS}

Description of the city - Recife, on $8^{\circ} 4^{\prime} 3$ " south latitude is the Capital of the State of Pernambuco, northeastern Brazil. An estimated population of $1.300,000$ people live within a $209 \mathrm{~km}^{2}$ area. The city is subdivided into 36 Special Zones of Social Interest (ZEIS), including 93 districts. About only $30 \%$ of the households are connected to an underground piped sewerage system. According to CONDEPE (1993), 49\% of the houses in the city are settled in slum areas. The city is crossed by three rivers and is at sea level.

The study area - The selected area for the survey included 21 of the 36 ZEIS (31 districts) and corresponded to 1.818 hectares $(8.3 \%$ of the city area), in which live a population of very low socioeconomic standing (Fig. 1).

The study population - The population included in the survey were all the persons living in the ZEIS, excluding the children under five years old, and persons over 65 years.

Sampling - Primary sampling units (blocks) were randomly selected, using maps obtained from the Municipal Planning Office, showing streets, avenues or structures on each block. The starting point for survey in each selected block was determined by randomly selecting a single house. Clusters of 10-25 households were then surveyed by moving from the starting point on the block to the nearest home in a clockwise fashion. Attempts were taken to ensure adequate geographic representation.

Blood collection - The blood was collected by thick smear technique, $60 \mu 1$ from each person, taken between 20:00-24:00 hr. The thick films were air dried overnight, dehaemoglobinized, fixed in methanol and stained with hematoxylin. $20 \%$ of all positive and negative slides were submitted to a quality control.

Results are expressed as the percentage of individuals with microfilaraemia, (mf rate) and microfilariae density per $60 \mu 1$ of blood (mf density).

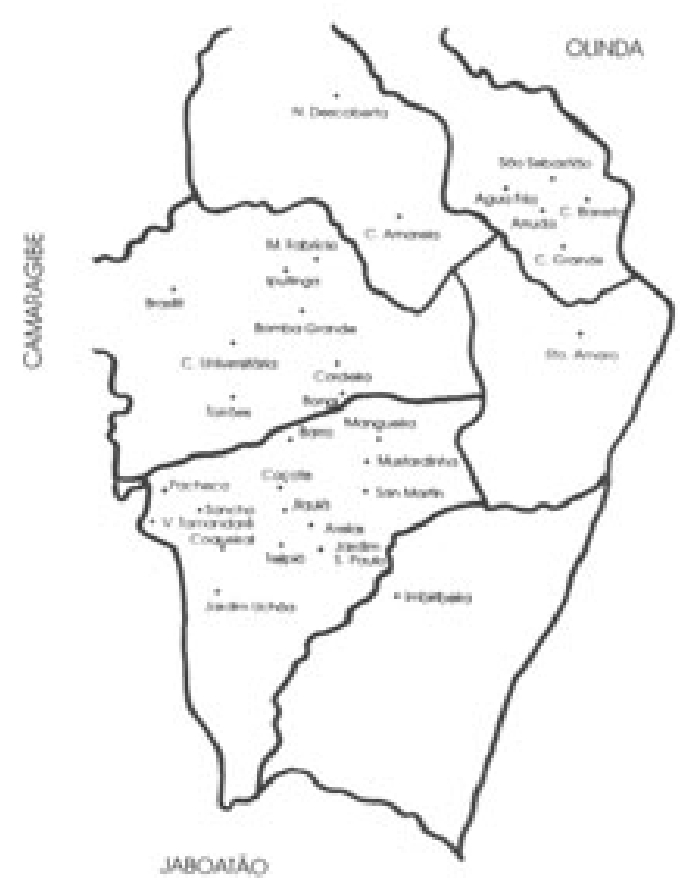

Fig. 1: districts of Recife, Brazil, where the filariasis survey was realized.

A clinical survey was also made. A team of physicians visited each household in an attempt to examine every individual in the study population for evidence of filarial disease.

Entomological survey - Entomological surveys are critical to the baseline evaluation of filarial transmission in the greater Recife area. It is assumed that Culex quinquefasciatus is the sole vector and that transmission occurs almost entirely domestic and peridomestic setting. In addition to breeding ecology, evaluations of imago density were assessed by standard methods such as the count of resting mosquitoes and by using CDCminiature light traps, settled both inside and outside the houses. The traps remained switched on overnight. The following morning the mosquitoes were collected and dissected to determine filarial infection and infectivity.

Methodology of the field work - The leaders of each community (ZEIS), were visited and the aim of the study was explained to them. At the same time they were told of the importance of their involvement in the program and of their help in gaining the confidence of the community. The population was invited to learn about the project and about filariasis, its transmission and control, through the presentation of videos, pamphlets and talks.

All positive patients were treated with diethylcarbamazine (DEC) according to WHO dosage: $6 \mathrm{mg} / \mathrm{kg}$ of body weight daily for $12 \mathrm{con}$ secutive days. 
Every 6 months after the treatment, a new sample of blood was collected from each person in order to check the presence or absence of $\mathrm{mf}$ and repeated courses of treatment were given to those still positive, until mf clearance was achieved.

\section{RESULTS}

From a total of 223 slum areas in Recife, 39 (26.4\%) were randomly selected for the survey, including 31 districts of the city. 3,595 houses were visited with a mean of 20 houses per cluster.

Of the 15,692 persons registered to the study 10,581 aged from 5 to 65 years old were examined by the technique of finger-prick blood samples. 1,717 were children under 5 years old and 3,394 refused to be examined.

The distribution of the population by sex and age showed that 5,844 were female and 4,737 were male, from which $52.2 \%$ aged from 5 to 24 years (Tahle I. Fio 2) 683 nersons were found nositive.

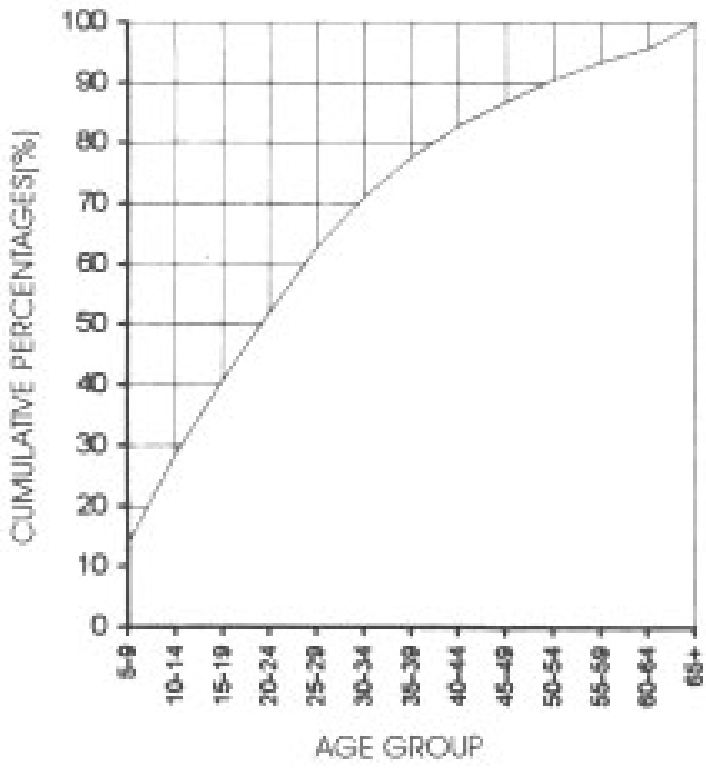

Fig. 2: distribution of microfilaraemia by age groups, Recife, Brazil, 1991. for $W$. bancrofti. The crude prevalence rate was $6.5 \%$, ranging from $0.6 \%$ to $14.9 \%$ according to the district (Fig. 3).

The $\mathrm{mf}$ rate distribution pattern, according to age and sex, showed that the infection occurs predominantly in persons aged between 15 to 29 years, and that it is predominant in males (Table I, Fig. 4).

The $\mathrm{mf}$ rate differences between the sexes were significant using the chi-square test, and the relative risk between male and female was $1.64<\mathrm{RR}<$ 2.20 (Greenland 1985).

Parasitic density ( $m f$ density) - The sum of microfilariae in all the 683 positive patients was 44,646 what gives a mean of $65,37 \mathrm{mf} /$ person/60 $\mu \mathrm{l}$ of blood and the $\mathrm{mf}$ density per $60 \mu \mathrm{l}$ ranged from 1 to 2289 (Table II ). The mf density in females was 54.4 and 72.48 in males. $18.3 \%$ presented densities ranging between $16-31 \mathrm{mf} / 60 \mu \mathrm{l}$ of blood. Densities over $50 \mathrm{mf} / 60 \mu \mathrm{l}$ were demonstrated in $26.8 \%$ of the mf carriers (Fig. 5).

Mosquitoes studies - Females of Culex quinquefasciatus were collected in 8 districts of the study area, 3 of which presented prevalences between $0.9-2.8 ; 2$ presented prevalences between 6.2 - 7.4 and the other 3 prevalences ranging from 10.4 to 14.9 . The number of mosquitoes collected varied from 85/house in Campo Grande to 1,229 mosquitoes/house in Cordeiro. The relationship among prevalence, $\mathrm{mf}$ density and infection/infectivity rate, was not significant, but the relationship between prevalence and infectivity rate was $(\mathrm{p}<$ $0.05)$ when applied the chi-square test.

\section{DISCUSSION}

The central point of the discussion about lymphatic filariasis in Recife, is the question if the endemy still is a public health problem and which is its impact on the affected population.

The disease was recognized as a public health problem since 1952, when its control was under

TABLE I

Distribution of microfilaraemia rate by age and sex. Recife Brazil, 1991

\begin{tabular}{crcrrrrrr}
\hline & \multicolumn{2}{c}{ Male } & & \multicolumn{2}{c}{ Female } & & \multicolumn{2}{c}{ Total } \\
\cline { 2 - 3 } \cline { 8 - 9 } Age group & No. Examined & No. Pos.(\%) & & No. Examined & No. Pos.(\%) & & No. Examined & No. Pos.(\%) \\
\hline $5-9$ & 764 & $25(3.3)$ & & 709 & $15(2.1)$ & & 1473 & $40(2.7)$ \\
$10-14$ & 765 & $42(5.5)$ & & 783 & $42(5.4)$ & & 1548 & $84(5.4)$ \\
$15-19$ & 619 & $72(11.6)$ & & 687 & $54(7.9)$ & & 1306 & $126(9.6)$ \\
$20-29$ & 1000 & $145(14.5)$ & & 1328 & $67(5.0)$ & & 2328 & $212(9.1)$ \\
$30-39$ & 642 & $62(9.7)$ & & 924 & $26(2.8)$ & & 1566 & $88(5.6)$ \\
$40-49$ & 389 & $33(8.5)$ & & 587 & $22(3.7)$ & & 976 & $55(5.6)$ \\
$50-59$ & 278 & $25(9.0)$ & & 418 & $17(4.1)$ & & 696 & $42(6.0)$ \\
+60 & 280 & $10(3.6)$ & & 408 & $26(6.4)$ & & 688 & $36(5.2)$ \\
\hline Total & 4737 & $414(8.7)$ & & 5844 & $269(4.6)$ & & 10581 & $683(6.5)$ \\
\hline
\end{tabular}




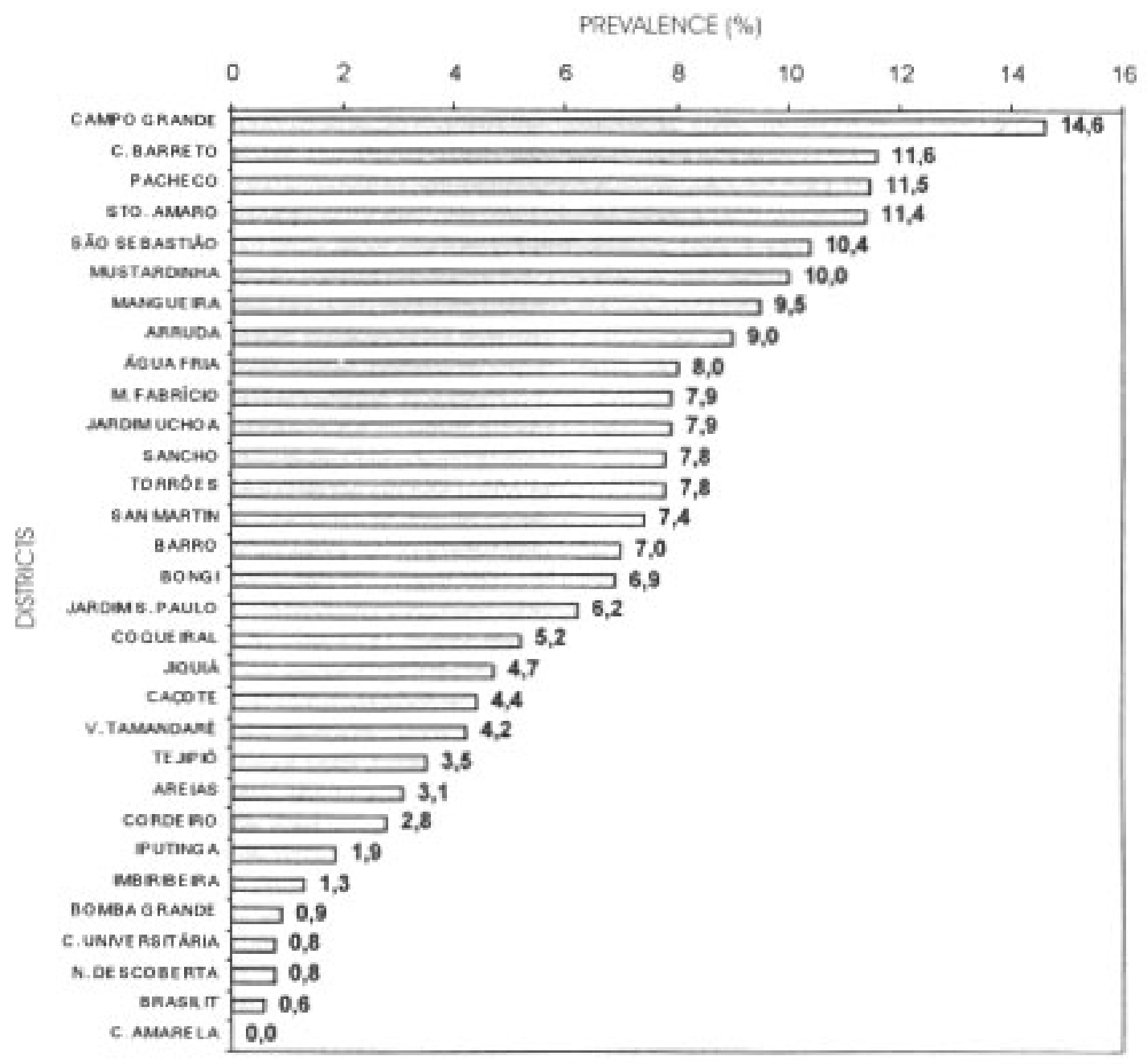

Fig. 3: microfilaraemia prevalence in 31 different districts of Recife, Brazil, 1991.

the responsibility of DNERu. These activities lasted for four decades, and in 1981 SUCAM's report to the ministry of health, it was shown that the endemy was under control, since the rate of prevalence recorded reached no more than $1.7 \%$. Morais (1982) pointed out that these results were based only on the analysis of crude data, once herself, analyzing a stratified population, found that in some districts of Recife, the endemy showed the same high rates of the past (10\%). The monthly reports from 1981 to 1989 on filariasis campaign held by SUCAM's Regional Directory of Pernambuco, showed very low microfilaraemic levels ranging from $0.6 \%$ (1985) to $2.1 \%$ (1989) (Table III).

The data obtained by Maciel et al. (1994) for Greater Recife besides to validate the high levels of filariasis prevalence found by Morais (1982), showed that the disease had spread to areas where it had never been noticed before. The existing discrepancy in the data recorded by Ministério da
Saúde (1981), Morais (1982) Maciel et al. (1994) and Furtado et al. (1994), may certainly be due to the methodology used to collect the blood. For some surveys, the blood films were made upon 5 drops of blood, and the finger prick was done between 8-12 p.m. Later on, only one drop of blood was taken very early in the night between 7-9 p.m.

Considering that the $W$. bancrofti, present in Recife, has a nocturnal periodicity, and the highest peak of microfilariae circulating in the blood was found between 10-11 p.m. (Furtado et al. in preparation), in this work, a measured thick blood smear $(60 \mu \mathrm{l})$ was collected between 8-12 p.m.

In spite of considering that the blood film method for evaluating microfilaraemia may result an underestimation (Southgate 1974, OMS 1988), the thick smear technique is still an useful tool for the evaluation of the magnitude of lymphatic filariasis infection in the overall population, if the periodicity of the parasite in the host, the amount 


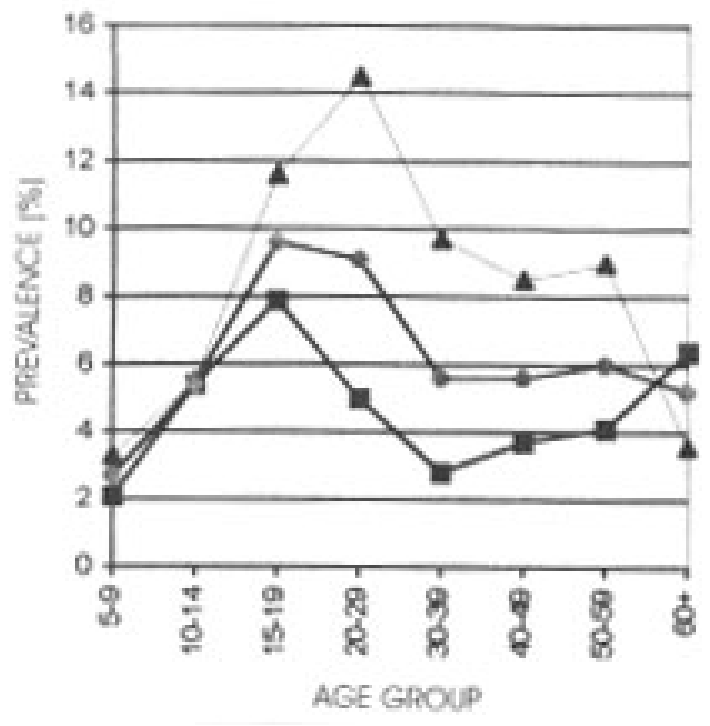

Fig. 4: microfilaraemia prevalence according to age group and sex in Recife, Brazil, 1991.

TABLE II

Frequency of microfilaraemia density per $60 \mu 1$ of blood. Recife, Brazil, 1991

\begin{tabular}{rcc}
\hline $\begin{array}{c}\text { Microfilaria Count } \\
(60 \mu \mathrm{l})\end{array}$ & $\begin{array}{c}\text { Number of } \\
\text { cases }\end{array}$ & $\begin{array}{c}\text { Cumulative }(\%) \\
\text { cases }\end{array}$ \\
\hline 1 & 58 & 8.5 \\
2 & 41 & 14.5 \\
3 & 20 & 17.4 \\
4 & 14 & 19.5 \\
5 & 16 & 21.8 \\
6 & 16 & 24.2 \\
7 & 19 & 26.9 \\
8 & 20 & 29.9 \\
9 & 12 & 31.6 \\
10 & 13 & 33.5 \\
$11-20$ & 95 & 47.4 \\
$21-30$ & 74 & 58.3 \\
$31-40$ & 43 & 64.6 \\
$41-50$ & 29 & 68.8 \\
$51-60$ & 25 & 72.5 \\
$61-70$ & 26 & 76.3 \\
$71-80$ & 20 & 79.2 \\
$81-90$ & 15 & 81.4 \\
$91-100$ & 17 & 83.9 \\
$101-200$ & 71 & 94.3 \\
$201-300$ & 22 & 97.5 \\
$301-400$ & 11 & 99.1 \\
$401-500$ & 4 & 99.7 \\
$501-600$ & - & 99.7 \\
$601-900$ & - & 99.7 \\
+901 & 2 & 100.0 \\
\hline Total & 683 & - \\
\hline & &
\end{tabular}

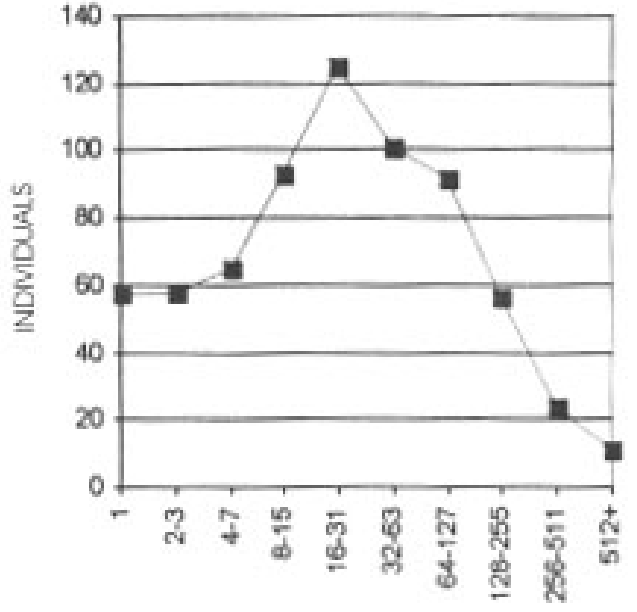

DENSIIIES

Fig. 5: microfilariae density in measured $(60 \mu 1)$ finger prick blood films taken between 8-12 p.m. Recife, Brazil, 1991.

TABLE III

Prevalence of Wuchereria bancrofti in Recife, Brazil, according to monthly reports from MS/SUCAM $(1989,1990)$

\begin{tabular}{cccc}
\hline Years & $\begin{array}{c}\text { Collected } \\
\text { slides }\end{array}$ & $\begin{array}{c}\text { Positive } \\
\text { slides }\end{array}$ & $\begin{array}{c}\% \text { of } \\
\text { positives }\end{array}$ \\
\hline 1981 & 290,135 & 4,816 & 1.7 \\
1982 & 290,914 & 4,549 & 1.6 \\
1983 & 210,711 & 2,029 & 1.0 \\
1984 & 205,298 & 1,365 & 0.7 \\
1985 & 200,764 & 1,268 & 0.6 \\
1986 & 103,969 & 1,403 & 1.3 \\
1987 & 76,900 & 661 & 0.9 \\
1988 & 101,992 & 1,423 & 1.4 \\
1989 & 95,467 & 20,354 & 2.1 \\
\hline
\end{tabular}

of blood to be collected, and if the existence of recent control programs in the area, are taken in consideration.

Undoubtfully the membrane filtration technique will remain the "gold standard" technique, nevertheless if one wants to accomplish surveys involving a great number of individuals, there are so many constraints associated with it, as cost-effectiveness, reluctance of the population to give a venous blood sample, and the time to process the blood, that it becomes impracticable.

The age and sex distribution of the microfilaraemia showing high prevalence in the young age group, clearly indicates the persistence of the transmission of $W$. bancrofti in Recife, with no major improvement since the 1980 's. Indeed, there has been an apparent increase in the overall prevalence since 1983. 
The only comparative data on the sex-age specific microfilaraemia prevalence in the other surveys was conducted by Causey (1945) in Belém, north of Brazil, which demonstrated a slightly higher rate in males.

In Recife, the only outstanding data, showed a high $\mathrm{mf}$ rate in persons aged between 10 and 19 years old (Azevedo \& Dobbin 1952), and between 20-49 years old (Ministério da Saúde 1981). Patterns of filariasis in human vary in different geographic areas. The prevalence of microfilaraemia usually increases with age. The epidemiological model of the sex and age distribution in Recife, doesn't differ too much from those described for other endemic areas in the world. It was very low in children aged between 5-9 years old, increased up to the ages of 30-39, and then showed a trend to decrease in older people. This pattern seems to be a general rule once similar behaviour was also mentioned by Sasa et al. (1976), Grove (1983), Rajagopalan et al. (1989) and Albuquerque (1995b), in different regions in the world.

Concerning sex differentials, in some locations rates of microfilaraemia are similar for both sexes, while in others, males are more affected. The pattern for Recife, is comparable to other endemic areas as some Asian countries like India and countries in eastern African coast. The infection in males was characterized by an increase with age (about 20-29 years old) followed by a fall until 60 or older people. The curve, for both sexes is similar up to the age of 15 to 19 years old. A decrease is observed in the age group 30 to 39 and it raises slightly in people aged 60 years or older. A similar pattern, with slight variations was found by Albuquerque et al. (1995a), studying two urban slums in Recife. The pattern of infection in women showed lower prevalence in the reproductive years as it was observed in other areas in the world (Rajagopalan et al. 1989, Brabin 1990, WHO 1992).

A mean of 65.3 microfilariae per $60 \mu 1$ of blood was found in Recife. This number is considered as an excellent parameter for the maintenance of filariasis transmission when the vector is Culex quinquefasciatus (Jayasekera et al. 1991, Southgate 1992). C. quinquefasciatus is the only vector implicated in the transmission of the urban filariasis in Recife, in spite of the presence of few breeding sites of Mansonia sp.

Since the 1970's, the rapid and chaotic ruralurban migration together with unplanned and uncontrolled urbanization in Recife, lead to an increase in the stagnated surface waters and drains. This contributed enormously to the successful breeding of $C$. quinquefasciatus in these areas, resulting in an increased transmission of urban bancroftian filariasis.

\section{ACKNOWLEDGMENTS}

To the National Health Foundation, Pernambuco State Health Secretary and Recife Health Secretary.

\section{REFERENCES}

Albuquerque MFM, Marzochi MC, Ximenes RAA, Braga MC, Silva MCM, Furtado AF 1995a. Bancroftian filariasis in two urban areas of Recife, Brasil: the role of individual risk factors. Rev Inst Med Trop São Paulo 373: 225-233.

Albuquerque MFM, Marzochi MC, Sabroza PC, Braga MC, Padilha T, Silva MCM, Silva MRF, Schindler HC, Maciel MA, Souza W, Furtado AF 1995b. Bancroftian filariasis in two urban areas of Recife, Brazil: pre-control observations on infection and disease. Trans R Soc Trop Med Hyg 105: 335-353.

Azevedo R, Dobbin Jr JE 1952. Filariose Wuchereria bancrofti no grupo residencial do IAPB no bairro dos Afogados (Recife). Publ Av Inst Aggeu Magalhães 1: 157-162.

Brabin L 1990. Sex differentials in susceptibility to lymphatic filariasis and implications for maternal child immunity. Epidemiol Infect 105: 335-352.

Causey OR, Deane, MP, Costa D, Deane LM 1945. Studies on incidence and transmission of filariasis Wuchereria bancrofti in Belém, Brazil. Am J Hyg 41:143-149.

CONDEPE (Instituto de Planejamento de Pernambuco) 1993. Perfil Sócio-Demográfico. Governo do Estado de Pernambuco, 61 pp.

Dreyer G, Medeiros Z 1990. Filariose linfática: ainda um desafio. Ciênc Hoje 12: 6-7.

Furtado AF, Maciel A, Rocha A, Regis L, Braga MC, Ferreira MR 1994. Controle da filariose na cidade do Recife: eficácia do tratamento em massa da população, utilizando baixas doses de dietilcarbamazina (DEC). Rev Soc Bras Med Trop 27: (supp I) 109.

Greenland R 1985. Confidence limits. Biometrics 41: 55-68.

Grove DI 1983. Selective primary health care: Strategies for the control of diseases in the developing world. VII. Filariasis. Rev Infect Dis 5: 933-944.

Jayasekera N, Kalpage KSP, Silva CSS 1991. The significance of the low density microfilaraemia in the transmission of Wuchereria bancrofti by Culex (Culex) quinquefasciatus Say in Sri Lanka .Trans $R$ Soc Trop M Hyg 85: 250-254.

Maciel A, Silva EC, Rocha A, Marzochi KB, Furtado A F 1994. Estudo comparativo da Filariose Bancroftiana em Região Metropolitana do Recife. Cad Saúde Pública 10 (supl 2): 301-309.

Morais HM 1982. A Filariose no Recife: Um estudo epidemiológico. MSc thesis, Universidade de São Paulo, São Paulo, 130 pp.

Moulia-Prelat JP, Glaziou P, Nguyen-Ngoc C, Spiegel A, Cartel JL 1992. A comparative study of detection methods for evaluation of microfilaraemia in lymphatic filariasis control programmes. Trop Med Parasitol 43: 146-148.

Ministério da Saúde 1981. Programa de Controle da 
Filariose. Relatório Anual. Recife: Superintendência de Campanhas de Saúde Pública.

Ministério da Saúde 1985. O controle das Endemias no Brasil (1979 a 1984). Brasília: Superitendência de Campanhas de Saúde Pública.

Ministério da Saúde 1990. Programa de Controle da Filariose. Relatório Anual. Recife: Superintendência de Campanhas de Saúde Pública. Diretoria Regional de Pernambuco.

OMS (Organização Mundial de la Salud) 1988. Lucha contra la filaríasis linfática - Manual para personal sanitario. Organización Mundial de la Salud, Genebra, 93 pp.

Parahym O 1961. Endemias Brasileiras (Bancroftose). Imprensa Universitária, Recife, Pernambuco, 547 pp.

Pessoa SB, Martins AV 1978. Parasitologia Médica. 10 ed. Editora Guanabara Koogan, Rio de Janeiro, $98 \mathrm{pp}$.

Rachou R, Deane LM 1954. Filariose humana no Brasil. Conhecimento atual de sua distribuição geográfica e transmissão. Rev bras Malariol D trop 6:377-387.
Rajagopalan PK, Das PK, Subramanian S, Vanamail P, Ramaiah KD 1989. Bancoftian filariasis in Pondicherry, South India. I. Pre-control epidemiological observations. Epidem Infect 103: 685-592.

Sasa M, Kanda T, Mitsui G, Shirisaka A, Ishii A, Chinzei H 1976. The filariasis control programmes in Japan and their evaluation by means of epidemiology analysis of the microfilaria survey data p. 3-72. In M Sasa, Recent advances in research on filariasis in Japan. University Park Press, Baltimore.

Southgate BA 1984. Recent advances in the epidemiology and control of filarial infections including entomological aspects of transmission. Trans $R$ Soc Trop Med Hyg 78: 19-27.

Southgate BA 1992. The significance of low density microfilaraemia in the transmission of lymphatic filarial parasites. J Trop Med Hyg 95: 79-86.

WHO (World Health Organization) 1992. Lymphatic filariasis. Fifth Report of the WHO Expert Committee on Filariasis (WHO Techical Report Series 821). WHO Geneva 73pp. 
Bancroftian Filariasis in Recife - Amélia Maciel et al. 